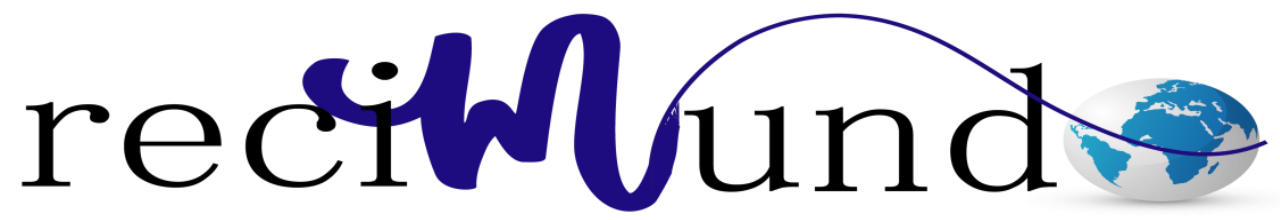

Revista Cientifica Mundo de la Investigación y el Conocimiento

Walter Alejandro Patiño Zambrano a; Alexandra Alvarado Álvarez ${ }^{\text {b }}$; Marco Alejandro Guerrero Casagualpa ${ }^{c}$; Tamara Yadira Segovia Buitrón ${ }^{\mathrm{d}}$

Detección oportuna del cáncer de cervix en mujeres en etapa sexual activa

Revista Científica Mundo de la Investigación y el Conocimiento. Vol. 2 núm., 1, febrero, ISSN: 2588-073X, 2018, pp. 645-657

DOI: 10.26820/recimundo/2.1.2018.645-657

Editorial Saberes del Conocimiento

Recibido: 05/12/2017 Aceptado: $15 / 02 / 2018$

a. Medico; Facultad de Ciencias Médicas; Universidad de Guayaquil; alejo8585@ hotmail.com

b. Universidad de Guayaquil; alexander.alvarado@ug.edu.ec

c. Medico; Facultad de Ciencias Médicas; Universidad de Central del Ecuador; marco88_08@ hotmail.com

d. Medico; Facultad de Ciencias Médicas; Universidad de Central del Ecuador; yadira17131317@gmail.com 


\section{Detección oportuna del cáncer de cervix en mujeres en etapa sexual activa}

Vol. 2, núm. 1., (2018)

Walter Alejandro Patiño Zambrano; Alexandra Alvarado Álvarez; Marco Alejandro Guerrero Casagualpa; Tamara Yadira Segovia Buitrón

\section{RESUMEN}

Sobre la detección oportuna del cáncer de cuello uterino, es preciso en primera instancia entender sus implicaciones, signos y síntomas, así como prevenirlo. Es por ello que este estudio se enfoca en generar un análisis bibliográfico, basado en textos y referencias de expertos en la materia y de acuerdo a las estadísticas existentes. En este sentido, vale la pena destacar que esta es una enfermedad íntimamente vinculada al virus del papiloma humano (VPH), por lo cual se hace imperante que las mujeres sexualmente activas se hagan las pruebas del VPH con regularidad, más en los casos donde no cuentan con una pareja estable, ya que incide en aumentar los niveles de riesgos en el posible padecimiento de esta enfermedad. Igualmente, los expertos recomiendan en aras de prevenir a futuro un posible cáncer de cérvix, que la paciente se vacune contra el VPH, cuyo carácter es profiláctico y no terapéutico, ya que no provee protección total contra todos los tipos de VPH. Sin embargo, fuentes de estudios, reflejan que un alto porcentaje del cáncer de cuello uterino, es producido por algunos tipos del VPH. No obstante, a pesar que la paciente se encuentre vacunada, debe practicarse un control ginecológico y las pruebas antes mencionadas, para efectivamente lograr la detección oportuna y por ende bajar la mortalidad por esta causa, ya que este tipo de cáncer, es uno de los de mayor incidencia en el género femenino.

Palabras claves: Cáncer, cervix, prevención, sexualidad, virus de papiloma humano, métodos de detección. 


\title{
Detección oportuna del cáncer de cervix en mujeres en etapa sexual activa
}

Vol. 2, núm. 1., (2018)

Walter Alejandro Patiño Zambrano; Alexandra Alvarado Álvarez; Marco Alejandro Guerrero Casagualpa; Tamara Yadira Segovia Buitrón

\begin{abstract}
On the timely detection of cervical cancer, it is necessary to understand its implications, signs and symptoms, as well as to prevent it. That is why this study focuses on generating a bibliographic analysis, based on texts and references from experts in the field and according to existing statistics. In this sense, it is worth noting that this is a disease closely linked to the human papillomavirus (HPV), which is why it is imperative that sexually active women get HPV tests regularly, more so in cases where they do not. They have a stable partner, as it affects increasing levels of risk in the possible suffering of this disease. Similarly, experts recommend for the future prevention of a possible cancer of the cervix, that the patient is vaccinated against HPV, whose character is prophylactic and not therapeutic, since it does not provide total protection against all types of HPV. However, sources of studies show that a high percentage of cervical cancer is produced by some types of HPV. However, despite the fact that the patient is vaccinated, gynecological control and the aforementioned tests must be practiced, in order to achieve timely detection and consequently lower mortality due to this cause, since this type of cancer is one of the of greater incidence in the feminine gender.
\end{abstract}

Keywords: Cancer, cervix, prevention, sexuality, human papilloma virus, detection methods. 


\section{Detección oportuna del cáncer de cervix en mujeres en etapa sexual activa}

Vol. 2, núm. 1., (2018)

Walter Alejandro Patiño Zambrano; Alexandra Alvarado Álvarez; Marco Alejandro Guerrero Casagualpa; Tamara Yadira Segovia Buitrón

\section{Introducción.}

Cáncer de cérvix es el tercer tipo de cáncer más común en las mujeres y sigue siendo la patología más frecuente en términos absolutos y por supuesto lo es ampliamente entre el género femenino, a pesar de que se trata de único tipo de cáncer al que se le han dedicado múltiples campañas de prevención y detección precoz desde más de 25 años (Pignataro, 2015). Según la (OMS, 2015) en el mundo se presentan alrededor de 500.000 nuevos casos por año y se producen alrededor de 250.000 muertes por esta causa. En el Ecuador se presentan alrededor de 1200 nuevos casos por año y mueren alrededor de 400 según los datos tomados del INEC y de los diferentes registros de cáncer publicados por los núcleos de SOLCA (Pignataro, 2015). En este sentido, el presente estudio se aboca en analizar por medio de textos y referencias bibliográficas sobre la detección oportuna del cáncer de cérvix principalmente en mujeres en etapa sexual activa, las causas más frecuentes de su aparición, síntomas, medidas de prevención y muy especialmente, hace énfasis en la información científica que deben manejar el mayor número de mujeres durante su etapa sexual, para evitar el cáncer y en caso de ser detectado un pre-cáncer, éste, no llegue a convertirse en un cáncer invasivo. Así mismo, refiere que una manera bien comprobada para prevenir el cáncer de cuello uterino, consiste en hacerse pruebas de Papanicolaou y la prueba del VPH.

A lo largo del artículo se hace mención igualmente, a la necesidad de aplicarse la vacuna del VPH y finalmente se refleja que la mayoría de los casos de cáncer invasivo de cuello uterino, se detecta en mujeres que no se han hecho con regularidad controles ginecológicos. 
Detección oportuna del cáncer de cervix en mujeres en etapa sexual activa

Vol. 2, núm. 1., (2018)

Walter Alejandro Patiño Zambrano; Alexandra Alvarado Álvarez; Marco Alejandro Guerrero Casagualpa; Tamara Yadira Segovia Buitrón

\section{Materiales y métodos.}

\section{Definición y etiología}

Cérvix: El cérvix o cuello uterino es la parte inferior del útero que forma el canal que lleva a la vagina. La mucosa que recubre el cérvix está en continuidad con la vagina y se denomina ectocérvix, mientras que la que recubre el conducto o canal cervical que lleva hasta la cavidad del cuello uterino, se denomina endocérvix. (Dávila Gómez, García Valdés, \& Álvarez Castillo, 2010).

Cáncer de cuello uterino: El cérvix o cuello uterino es la parte inferior del útero que forma el canal que lleva a la vagina. La mucosa que recubre el cérvix está en continuidad con la vagina y se denomina ectocérvix, mientras que la que recubre el conducto o canal cervical que lleva hasta la cavidad del cuello uterino, se denomina endocérvix._En este tipo de cáncer, la mayor parte de los tumores surgen en la zona donde se une el ectrocérvix con el endocérvix dando lugar a carcinomas de células escamosas (Dávila Gómez, García Valdés, \& Álvarez Castillo, 2010)

Figura $N^{\circ} 1$. Imagen del aparato reproductiva de la mujer.
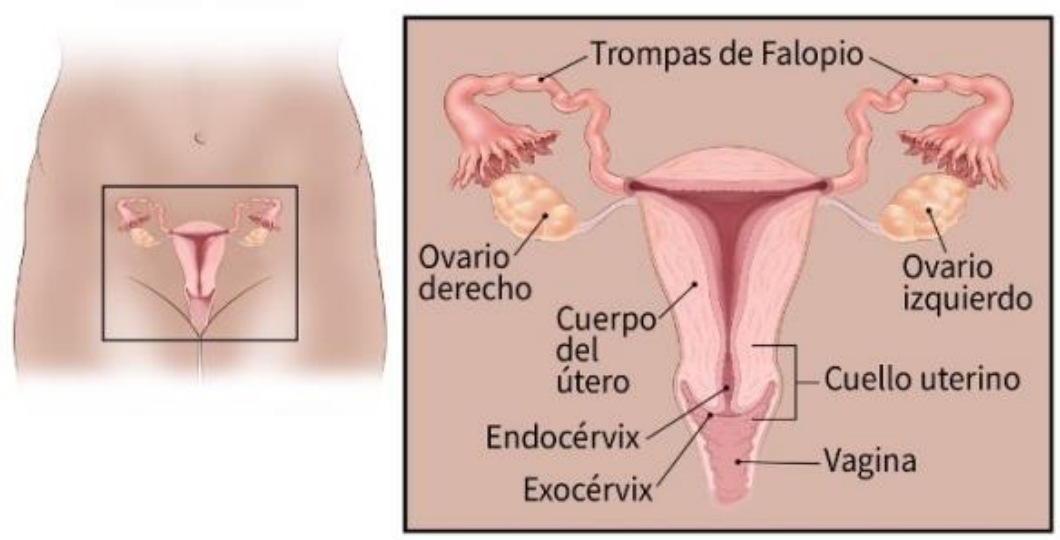

Fuente: (ACS, 2014) 


\section{Detección oportuna del cáncer de cervix en mujeres en etapa sexual activa}

Vol. 2, núm. 1., (2018)

Walter Alejandro Patiño Zambrano; Alexandra Alvarado Álvarez; Marco Alejandro Guerrero Casagualpa; Tamara Yadira Segovia Buitrón

El cáncer se produce cuando las células normales del cuello del útero empiezan a transformarse y crecen de manera descontrolada.

\section{$\underline{\text { Tipos }}$}

Existen 2 tipos de células en la superficie del cuello uterino: escamosas y columnares. La mayoría de los cánceres de cuello uterino provienen de las células escamosas: (en el exocérvix) y las células glandulares (en elendocérvix). El punto en el que estos tipos de células se encuentran se llama zona de transformación. La ubicación exacta de la zona de transformación cambia a medida que la paciente envejece y tiene hijos (Miami Health Institute, n.ed). Los cánceres de cuello uterino se clasifican de acuerdo con el aspecto que presentan bajo el microscopio.

En este sentido, cabe destacar que existen dos tipos principales de cáncer de cuello uterino: el carcinoma de células escamosas y el adenocarcinoma. Aproximadamente un $80 \%$ a 90\% de los cánceres de cuello uterino son carcinomas de células escamosas. Estos cánceres se originan de células en el exocérvix y las células cancerosas tienen características de las células escamosas cuando se observan con un microscopio (ACS, 2014)

La mayoría de los tipos de cáncer de cuello uterino (cervicales) restantes son adenocarcinomas. Los adenocarcinomas son cánceres que se originan de células glandulares. El adenocarcinoma cervical se origina en las células de las glándulas productoras de mucosidad del endocérvix. Los adenocarcinomas cervicales parecen haberse hecho más comunes en los últimos 20 a 30 años (Dávila Gómez, García Valdés, \& Álvarez Castillo, 2010). Con menor frecuencia, el cáncer de cuello uterino tiene características tanto de los carcinomas de células escamosas 


\section{Detección oportuna del cáncer de cervix en mujeres en etapa sexual activa}

Vol. 2, núm. 1., (2018)

Walter Alejandro Patiño Zambrano; Alexandra Alvarado Álvarez; Marco Alejandro Guerrero Casagualpa; Tamara Yadira Segovia Buitrón

como de los adenocarcinomas. Estos tumores se llaman carcinomas adenoescamosos o carcinomas mixtos (CDC, 2017).

Signos y sintomas

De acuerdo a (ACS, 2014) las mujeres con cánceres de cuello uterino en etapa temprana usualmente no presentan síntomas. Los síntomas a menudo no comienzan hasta que un precáncer se torna en un cáncer invasivo verdadero y crece hacia el tejido adyacente. Cuando esto ocurre, los síntomas más comunes son:

- Sangrado vaginal anormal: Tal como sangrado después de sostener relaciones sexuales (coito vaginal), sangrado después de la menopausia, sangrado y manchado entre periodos y periodos menstruales que duran más tiempo o con sangrado más profuso de lo usual. El sangrado después de una ducha vaginal o después del examen pélvico es un síntoma común del cáncer de cuello uterino (MedlinePlus, 2015).

- Una secreción vaginal inusual (la secreción puede contener algo de sangre y se puede presentar entre sus periodos o después de la menopausia) (CDC, 2017).

- Dolor durante las relaciones sexuales (coito vaginal) (Dávila Gómez, García Valdés, \& Álvarez Castillo, 2010).

- Dolor de espalda, piernas o pélvico.

- Cansancio, pérdida de peso, pérdida de apetito.

- Hinchazón de una sola pierna. 


\section{Detección oportuna del cáncer de cervix en mujeres en etapa sexual activa}

Vol. 2, núm. 1., (2018)

Walter Alejandro Patiño Zambrano; Alexandra Alvarado Álvarez; Marco Alejandro Guerrero Casagualpa; Tamara Yadira Segovia Buitrón

En virtud de los anterior es importante mencionar que la paciente puede presentar estos síntomas y no padecer de esta patología, por lo cual debe siempre ante cualquier duda con su médico tratante. De igual manera la (OMS, 2015) señala que lo que si suele ser vinculante al momento de descartar un posible padecimiento de esta enfermedad son las infecciones por virus de papiloma humano (VPH), las cuales suelen ser asintomáticas o pasan desapercibidas, y se resuelven de forma espontánea. Sin embargo, las infecciones persistentes provocadas por determinados tipos de VPH pueden dar lugar a lesiones precancerosas, que, si no se tratan, pueden evolucionar hacia un cáncer de cuello uterino (CCU), aunque ese proceso suele durar muchos años.

Figura $N^{\circ}$ 2. Tasas de cáncer de cuello uterino asociada al VPH por raza y grupo étnico.

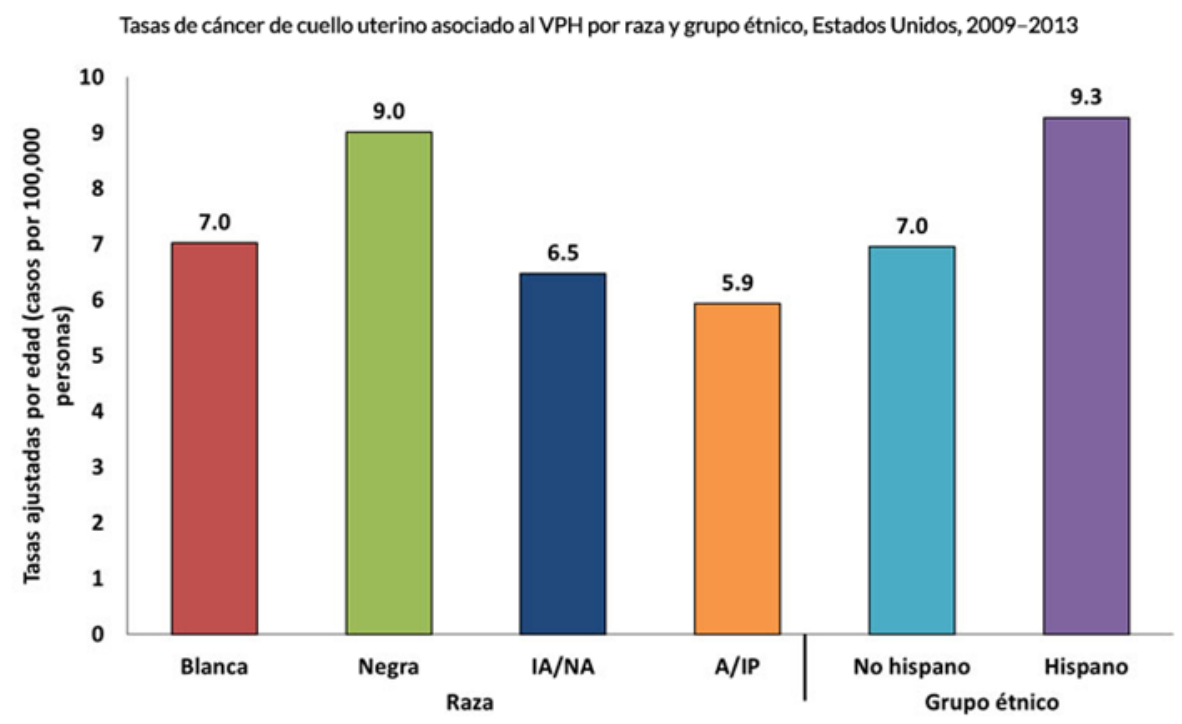

Fuente: (CDC, 2017) 


\section{Detección oportuna del cáncer de cervix en mujeres en etapa sexual activa}

Vol. 2, núm. 1., (2018)

Walter Alejandro Patiño Zambrano; Alexandra Alvarado Álvarez; Marco Alejandro Guerrero Casagualpa; Tamara Yadira Segovia Buitrón

\section{Alcance del problema}

A nivel mundial, el CCU es el cuarto cáncer más frecuente en la mujer. Se calcula que en 2012 hubo 530000 nuevos casos, que representaron el 7,5\% de la mortalidad femenina por cáncer. De las aproximadamente 270000 defunciones por CCU que se registran cada año, más del 85\% se producen en los países en desarrollo (OMS, 2015). En los países desarrollados, se han puesto en marcha programas que permiten que las mujeres se sometan a pruebas de detección de la mayor parte de las lesiones precancerosas en fases en que todavía pueden tratarse fácilmente. En esos países el tratamiento precoz previene hasta el $80 \%$ de los casos de CCU (OMS, 2015).

En los países en desarrollo, el escaso acceso a pruebas de detección eficaces significa que, con frecuencia, la enfermedad no se detecta hasta las fases más avanzadas, cuando aparecen los síntomas. Además, las perspectivas de tratamiento de la enfermedad en una fase tan avanzada no siempre son buenas, por lo que en estos países la tasa de mortalidad por CCU es más alta (Pignataro, 2015) La elevada tasa de mortalidad mundial por CCU (52\%) podría reducirse con programas de detección y tratamiento eficaces. (OMS, 2015).

\section{Causas}

Los cánceres cervicales comienzan en las células de la superficie del cuello uterino. El desarrollo del cáncer cervical generalmente es muy lento y comienza como una afección precancerosa llamada displasia. Esta afección se puede detectar por medio de una citología vaginal y es $100 \%$ curable. Pueden pasar años para que la displasia se convierta en cáncer cervical. La mayoría de las mujeres a quienes se les diagnostica cáncer cervical en la actualidad, 


\section{Detección oportuna del cáncer de cervix en mujeres en etapa sexual activa}

Vol. 2, núm. 1., (2018)

Walter Alejandro Patiño Zambrano; Alexandra Alvarado Álvarez; Marco Alejandro Guerrero Casagualpa; Tamara Yadira Segovia Buitrón

no se han sometido a citologías vaginales regulares, o, no han tenido un seguimiento por resultados anormales en estas (ACS, 2014).

Asimismo, se debe hacer mención que los hábitos y patrones sexuales de una mujer pueden aumentar su riesgo de padecer cáncer cervical. Las prácticas sexuales riesgosas incluyen: Tener relaciones sexuales a una edad temprana, tener múltiples parejas sexuales o tener una pareja o múltiples parejas que participen en actividades sexuales de alto riesgo (OMS, 2015).

Otros factores de riesgo del cáncer cervical incluyen: No recibir la vacuna contra el VPH, estar en condiciones económicas desfavorables, tener una madre que haya tomado durante su embarazo el medicamento DES (dietilestilbestrol) a comienzos de los años 60 para prevenir el aborto espontáneo, sistema inmunitario debilitado (MedlinePlus, 2015)

\section{Resultados.}

Una manera bien comprobada para prevenir el cáncer de cuello uterino consiste en hacerse pruebas de Papanicolaou y las pruebas del virus del papiloma humano (VPH). Si se encuentra un pre-cáncer, se puede tratar, para detener el cáncer de cuello uterino, antes de que realmente comience. Debido a que la vacuna del VPH no provee protección total contra todos los tipos de VPH que pueden causar cáncer de cuello uterino, es muy importante que las mujeres continúen haciéndose las pruebas de detección del cáncer de cuello uterino, incluso después de haber sido vacunadas. La mayoría de los casos de cáncer invasivo de cuello uterino, se detecta en mujeres que no se han hecho con regularidad controles ginecológicos (OMS, 2015). 


\section{Detección oportuna del cáncer de cervix en mujeres en etapa sexual activa}

Vol. 2, núm. 1., (2018)

Walter Alejandro Patiño Zambrano; Alexandra Alvarado Álvarez; Marco Alejandro Guerrero Casagualpa; Tamara Yadira Segovia Buitrón

\section{Prevención temprana}

Evite el contacto con el virus del papiloma humano (VPH): Debido a que el Virus del Papiloma Humano (VPH) es la principal causa del cáncer de cuello uterino, evitar la exposición al mismo podría ayudar a prevenir esta enfermedad. El VPH se transmite de una persona a otra durante el contacto de piel a piel con una zona infectada del cuerpo, incluso es posible que una infección genital se transmita al tocar los genitales con las manos. Asimismo, se puede propagar durante la relación sexual, que incluye el contacto vaginal, el anal y el sexo oral, no tiene que ocurrir el acto sexual para que la infección se propague. Esto significa que el virus se puede transmitir a través del contacto de genital a genital (sin coito) (OMS, 2015).

Las mujeres que han tenido muchas parejas sexuales tienen una mayor probabilidad de infectarse, aunque una mujer que haya tenido solo una pareja sexual también puede infectarse con el virus. Esto es más probable que ocurra si ella tiene una pareja que ha tenido muchas parejas sexuales o si su pareja es un hombre que no ha sido circuncidado (CDC, 2017).

$\underline{\text { Uso de condones: }}$ El uso de preservativos, llámese condones, no solo se usa para la planificación familiar y evitar las enfermedades de transmisión sexual (ETS), sino que, coadyuva en la prevención del cáncer de cuello uterino, proporcionando cierta protección contra el VPH; pero no pueden prevenir completamente las infecciones. Según (OMS, 2015) un estudio encontró que cuando se usan los condones correctamente cada vez que se tiene sexo, éstos pueden reducir la tasa de infección con VPH en aproximadamente 70\%, una de las razones por las que los condones no pueden ofrecer protección total es porque no pueden cubrir todas las áreas del cuerpo que pueden infectarse con VPH, tal como la piel del área genital o anal. 


\section{Detección oportuna del cáncer de cervix en mujeres en etapa sexual activa}

Vol. 2, núm. 1., (2018)

Walter Alejandro Patiño Zambrano; Alexandra Alvarado Álvarez; Marco Alejandro Guerrero Casagualpa; Tamara Yadira Segovia Buitrón

No fume: Evitar fumar es otra forma importante de reducir el riesgo de cáncer de cuello uterino (ACS, 2014).

Vacunarse: Hay vacunas disponibles para protegerse contra la infección del VPH. Todas estas vacunas ofrecen protección contra la infección de los subtipos 16 y 18 del VPH. Algunas también pueden ofrecer protección contra la infección de otros subtipos del VPH, incluyendo algunos tipos causantes de verrugas anales y genitales (Pérez, 2006).

Estas vacunas funcionan solamente para prevenir la infección contra el VPH (no son un tratamiento de una infección ya existente). Por esta razón, para una óptima eficacia, la vacuna contra el VPH se debe aplicar antes de que una persona se exponga, es decir, preferiblemente antes de que la persona sea sexualmente activa (ACS, 2014).

\section{Conclusiones.}

El cáncer de cérvix o de cuello uterino definitivamente es una patología que afecta a millones de mujeres a nivel mundial, lo interesante de notar es que hoy en día aproximadamente la mitad son infiltrantes y la otra mitad intra epiteliales, y cuando se miran las curvas de tendencias se observa que desde alrededor del año 1996 se produce una disminución progresiva de la incidencia de las lesiones infiltrantes y un incremento de registro de lesiones intra epiteliales de alto grado en Ecuador (Pignataro, 2015). A pesar de los esfuerzos que se han hecho en materia educativa para formar a las mujeres a temprana edad sobre el padecimiento de este tipo de enfermedad, se sigue observando un importante número de casos avanzados y la mortalidad aún es alta, lo que significa que hay un significativo grupo de mujeres a las que el 


\section{Detección oportuna del cáncer de cervix en mujeres en etapa sexual activa}

Vol. 2, núm. 1., (2018)

Walter Alejandro Patiño Zambrano; Alexandra Alvarado Álvarez; Marco Alejandro Guerrero Casagualpa; Tamara Yadira Segovia Buitrón

mensaje de las campañas aún no le llega y que la terapéutica actual a pesar de su sofisticación en estos casos no es totalmente efectiva (Dr. Pignataro, 2008).

Por otro lado, la aparición en el mercado de la vacuna contra VPH introduce un nuevo elemento en la lucha contra el CCU, pese a ser una vacuna de uso profiláctico y no terapéutico cuyo costo en Ecuador es de $\$ 510$, las 3 dosis necesarias (Pignataro, 2015). Sin embargo, es importante mantener las estrategias de prevención y detección precoz, buscando la manera de tener un mayor alcance (CDC, 2017). De igual manera se considera prudente contar con un sistema integrado que aproveche la infraestructura sanitaria ya existente, permitiendo un trabajo conjunto de las diferentes instituciones que trabajan en el tema (ACS, 2014).

\section{Bibliografía.}

ACS. (2014). ¿Qué es cáncer de cuello uterino (cervical)? Georgia: Sociedad Americana Contra el Cáncer.

CDC. (2017). El virus del papiloma humano (VPH) y el cáncer. Atlanta: Centers for Disease Control and Prevention.

Dávila Gómez, H., García Valdés, A., \& Álvarez Castillo, F. (2010). Cáncer de cuello uterino. Revista Cubana de Obstetricia y Ginecología, 36(4), 603-612.

MedlinePlus. (2015). Cáncer cervical. Bethesda: Información de Salud de la Biblioteca Nacional de Medicina.

OMS. (2015). Papilomavirus humanos (PVH) y cáncer cervicouterino. Ginebra: Organización Mundial de la Salud.

Pérez, M. (2006). Ginecología Oncológica Pelviana. Primera Parte. La Habana: Editorial Ciencias Médicas.

Pignataro, M. (2015). Cáncer de Cuello Uterino en el Ecuador. Medicos Ecuador, 15(2), 15-30. 